\title{
NONBREEDING HABITAT OCCUPANCY AND POPULATION PROCESSES: AN UPGRADE EXPERIMENT WITH A MIGRATORY BIRD
}

\author{
Colin E. Studds ${ }^{1,2,3}$ And Peter P. Marra ${ }^{2}$ \\ ${ }^{1}$ Program in Behavior, Ecology, Evolution, and Systematics, University of Maryland, College Park, Maryland 20742 USA \\ ${ }^{2}$ Smithsonian Environmental Research Center, P.O. Box 28, Edgewater, Maryland 21037 USA
}

\begin{abstract}
Evidence is accumulating that winter habitats occupied by migratory birds produce differences in individual condition that can carry over into subsequent stages of the annual cycle. Despite strong observational evidence, experimental work is needed to strengthen support for this hypothesis. We experimentally upgraded individual American Redstarts (Setophaga ruticilla) from low-quality second-growth scrub habitat to high-quality mangrove forest habitat by permanently removing behaviorally dominant, primarily adult males from mangrove, allowing females and immature males from scrub to colonize vacated territories. Prior to the manipulation, upgraded and control redstarts had stable-carbon isotope values in their blood indicative of scrub habitat occupancy and were comparable in body mass. Relative to control birds that overwintered exclusively in scrub, upgraded redstarts incorporated mangrove isotopic signatures, maintained body mass from winter to spring, departed earlier on spring migration, and returned at a higher rate in the following winter. Furthermore, insect biomass on upgrade territories was significantly greater than on control territories, suggesting food availability as a proximate mechanism underlying gradients of nonbreeding habitat suitability. Findings here demonstrate that winter habitat occupancy can be an important determinant of individual performance in migratory birds. Restricted access to food-rich winter habitats may limit survival of females and immature males, an outcome that could be an important driver of population structure and dynamics.

Key words: American Redstart; carryover effects; experimentally upgraded territories; migratory birds; nonbreeding winter habitat; population dynamics; removal experiments; seasonal interactions; Setophaga ruticilla; stable-carbon isotopes.
\end{abstract}

\section{INTRODUCTION}

Migratory animals move between geographically disparate habitats to meet seasonally changing needs, a process that may produce a suite of pressures on population dynamics. Nearctic-Neotropical migratory passerine birds spend three to four months on their temperate breeding grounds, about one to two months each on spring and fall migration, and six to seven months on their tropical winter quarters. Because of the spatially disjunct nature of these habitats and the difficulty of tracking individuals between seasons, contention remains about when population limitation occurs in the annual cycle (Rappole and McDonald 1994, Latta and Baltz 1997, Newton 2004). Much of the evidence for breeding-season limitation comes from research on forest loss and fragmentation, including effects on food supply (Burke and Nol 1998, Zanette et al. 2000), nest predation and parasitism (Robinson et al. 1995, Rodewald and Yahner 2001), and annual survival (Bayne and Hobson 2002). Other evidence suggests that migratory birds may be limited by events

Manuscript received 19 July 2004; revised 19 January 2005; accepted 14 March 2005. Corresponding Editor: J. R. Walters.

${ }^{3}$ Address correspondence to Colin E. Studds, SERC, P.O. Box 28, Contees Wharf Rd., Edgewater, Maryland 21037-0028 USA. E-mail: studdsc@si.edu during migration (Moore et al. 1995, Sillett and Holmes 2002) or by food availability on tropical winter areas (Strong and Sherry 2000, Latta and Faaborg 2002).

A more holistic model for examining migratory bird population dynamics has emerged recently with the demonstration of carryover effects (Marra et al. 1998, Gill et al. 2001, Møller et al. 2004, Norris et al. 2004a, $b)$. Carryover effects occur when ecological factors limit individual condition in one part of the annual cycle and thereby alter the timing or capacity of an individual to migrate, reproduce, or survive in a subsequent stage (Runge and Marra 2005, Marra et al., in press). Recent work demonstrates that individuals with multiple failed nest attempts, or those that fledge offspring in late summer, may delay molt until during fall migration (Norris et al. 2004b). However, most studies to date have examined carryover effects originating during the winter portion of the annual cycle. Occupancy of poor-quality winter habitats has been shown to adversely affect physical condition during migration (Bearhop et al. 2004), arrival date and condition at breeding sites (Marra et al. 1998, Gill et al. 2001), and reproductive success (Norris et al. 2004a). Elucidating how winter habitats determine individual performance and the process by which they produce carryover effects therefore may be critical for understanding population dynamics of migratory birds. 
In Jamaica, behaviorally dominant (predominantly adult male) American Redstarts (Setophaga ruticilla, a Neotropical-Nearctic migratory bird) exclude subordinates (mostly females and immature males) from black mangrove forest, forcing them to occupy secondgrowth scrub habitat (Marra et al. 1993, Marra 2000). Long-term, observational data have shown that redstarts overwintering in mangrove, regardless of age or sex, maintain body mass throughout the winter period, depart earlier on spring migration, and have higher annual return rates compared to birds residing in scrub habitat (Marra et al. 1998, Marra and Holmes 2001). Although these findings strongly suggest that individual performance is determined by nonbreeding habitat occupancy, experimental work is needed to strengthen support for this hypothesis.

In 2002 and 2003, we experimentally upgraded primarily female and immature male American Redstarts from dry, second-growth scrub to mesic mangrove habitat. Previous removal experiments in this system were designed to test for floaters and for mechanisms underlying sexual habitat segregation (Marra et al. 1993, Marra 2000). Research presented here builds upon this work, but differs in that we have not, until now, monitored the ecological consequences of these manipulations on individual performance.

To demonstrate that upgraded individuals originated from scrub and to confirm that they successfully persisted in mangrove territories, we measured stable-carbon isotopes signatures in blood, a reliable indicator of habitat occupancy (Marra et al. 1998), both before and after experimental upgrades. In addition, we sampled insect food availability to assess the proximate mechanism underlying gradients of nonbreeding habitat suitability. We predicted that upgraded redstarts would develop stable-carbon isotope signatures to reflect mangrove habitat occupancy, maintain body mass over winter, depart earlier on spring migration, and return at a higher rate in the following year relative to control birds overwintering exclusively in scrub.

\section{Methods}

Our research was conducted on the southwestern coast of Jamaica at the Font Hill Nature Preserve $\left(18^{\circ} 02^{\prime} \mathrm{N}, 77^{\circ} 57^{\prime} \mathrm{W}\right), \sim 13 \mathrm{~km}$ west of Black River, St. Elizabeth Parish and $5 \mathrm{~km}$ east of Whitehouse, Westmoreland Parish. This area is one of the driest in Jamaica, with $<1000 \mathrm{~mm}$ of rain per year. Most of the rainfall occurs between August and November, when monthly precipitation typically exceeds $100 \mathrm{~mm}$. Rainfall declines to $<25 \mathrm{~mm} /$ month after November, and by late February and early March, drought conditions prevail throughout much of the area (Petroleum Corporation of Jamaica, unpublished data).

American Redstarts were studied in two habitat types: coastal mangrove forest and second-growth scrub. Mangrove forest was dominated by black mangrove (Avicennia germinans), but also contained patch- es of white (Languncularia racemosa) and red mangrove (Rhizophora mangle). Mangrove stands had a nearly continuous canopy averaging $12 \mathrm{~m}$ in height, with little shrub- and ground-level vegetation, except for mangrove pneumatophores, which grew to $<20 \mathrm{~cm}$. In early winter, mangrove trees were flooded with up to $1 \mathrm{~m}$ of water. Although water levels dropped with the onset of the dry season, pools of standing water remained through the spring and mangroves retained their leaves, keeping this habitat comparatively shady and cool. Second-growth scrub consisted mainly of logwood trees (Haematoxylon campechianum), but also had other species including Bursera simarubra, Terminalia latifolia, and Crescentia alata. Disturbance from cattle grazing and tree harvesting created a mosaic of vegetation types, with grassy fields in recently impacted areas and dense clusters of vines, shrubs, and trees with canopies ranging from 3 to $10 \mathrm{~m}$ in older sites. Unlike mangrove habitat, second-growth scrub never had standing water; as the dry season progressed, this habitat became increasingly arid and most plants shed their leaves. Further description of the study area is available in Marra and Holmes (2001).

Six study sites were used, three 5-ha control sites consisting entirely of second-growth scrub and three 3 -ha upgrade sites, which encompassed $\sim 1.5$ ha each of mangrove and scrub habitat. The transition between mangrove and scrub habitats at these sites was abrupt and could be accurately delineated by the upper extent of mangrove pneumatophore growth. The spatial proximity of scrub and mangrove habitats on the upgrade sites ensured that redstarts in scrub could monitor and exploit experimentally created vacancies in mangrove as soon as they were available. Upgrade sites were separated by $>400 \mathrm{~m}$, and were $\sim 500 \mathrm{~m}$ from the nearest scrub control site. The scrub control sites were $>500 \mathrm{~m}$ from one another. All sites were flagged at 25-m intervals to facilitate locating and mapping redstart territories.

In winter (15 January-20 February) of 2002 and 2003 , redstarts in control sites and in the scrub portion of upgrade sites were captured in mist nets, aged and sexed using criteria from Pyle (1997) and Marra et al. (1993), fitted with a unique color scheme of plastic leg bands and USFWS aluminum bands, measured for body size (bill dimensions, wing, tail, and tarsus), weighed to the nearest $0.1 \mathrm{~g}$, bled for stable-carbon isotope signatures, and released. Color-banded birds were followed and mapped for a minimum of three personhours. Within a day of completing mapping observations, all behaviorally dominant, primarily adult male redstarts residing on the 1.5-ha mangrove section of upgrade sites were captured and sacrificed by thoracic compression. In this way, we created vacant mangrove territories, providing the opportunity for redstarts from scrub to upgrade to mangrove habitat.

In spring (20 March-15 April) of 2002 and 2003, after the onset of the winter dry season, we attempted

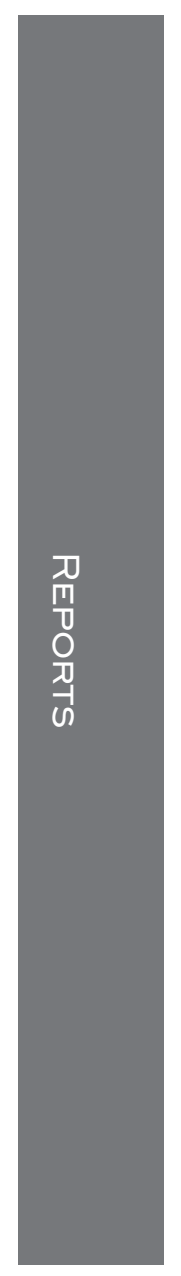


to recapture, reweigh, and take a second blood sample for all upgraded and control birds. Beginning on 1 April of each year, we resighted all upgraded and control individuals at 3-day intervals to determine the timing of migratory departure. When observers failed to resight a bird, its territory was visited twice more during that 3-day period, and then once again in the next 3day period using a song-chip playback to confirm departure. In 2003 and 2004, we conducted intensive resight and recapture efforts to determine the number of control and upgrade birds that had returned from the previous winter.

Insect food availability was measured on upgrade and control territories in winter (15 January-20 February) and again in spring (20 March-15 April) on territories of all recaptured birds. One observer made 20 passes of a sweep net over green vegetation while walking a circular route through the territory. The sweep net was fastened to a 5-m extension pole, allowing insects to be sampled from within the foraging height range of redstarts. The contents of the sweep net were overturned into a plastic bag and placed overnight in a freezer $\left(-10^{\circ} \mathrm{C}\right)$. Insects were then sorted to taxonomic order, preserved in $70 \%$ ethanol, dried at $50^{\circ} \mathrm{C}$ for 24 hours, adjusted to reflect redstart diet preference (Sherry and Holmes 1997), and weighed ( $\pm 0.1 \mathrm{mg}$ ).

Blood samples were kept on ice in the field and centrifuged to separate plasma and hematocrit components. For isotope analysis, the hematocrit portion of each sample was freeze-dried, powdered, packaged in tin capsules, and weighed to the nearest $1 \mu \mathrm{g}$. Samples were combusted in a Europa ANCA-GSL Elemental Analyzer and introduced online into a Europa Hydra 20/20 Isotope Ratio Mass Spectrometer (Europa Scientific, Cambridge, UK). One in-house standard was run for every six unknowns. All analyses were done at the University of California-Davis Stable Isotope Facility. Isotope values (unknown, "unk") are expressed in $\delta$ units relative to a Pee Dee belemnite standard ("std") where

$$
\delta^{13} \mathrm{C}=\left\{\left[\left(\delta^{13} \mathrm{C}_{\mathrm{unk}} / \delta^{12} \mathrm{C}_{\mathrm{unk}}\right) /\left(\delta^{13} \mathrm{C}_{\mathrm{std}} / \delta^{12} \mathrm{C}_{\mathrm{std}}\right)\right] \times 1000\right\} .
$$

Samples were repeatable to within $\pm 0.2 \%$ o $(n=20$ standards) based on repeated measurements of standards.

Data on stable-carbon isotope values, redstart body mass, and insect biomass were examined using a repeated-measures mixed model with year (2002 and 2003) and treatment (upgraded and control redstarts) as main effects and time (pre- and post-upgrade) as the repeated measure. Wing length (unflattened wing chord) was included in the model as a covariate to yield an estimate of mass corrected for the body size of each redstart. Individual bird nested within treatment was considered a random effect. The relationship between overwinter body mass change and migratory departure date was tested with ordinary least squares regression. Departure schedules were analyzed with a Kaplan-
Meier log-rank test. Return rate data were examined with Pearson's chi-square test. All data met test assumptions, so no transformations were used. Analyses were done with SAS 8.2 (SAS Institute 1999).

\section{RESULTS}

In 2002 and 2003 combined, 28 American Redstarts were removed from their territories in mangrove habitat ( $n=4$ adult females; $n=9$ yearling males; $n=15$ adult males). Mapping observations indicated that 23 individuals shifted from second-growth scrub habitat to experimentally vacated mangrove territories $(n=7$ yearling females; $n=8$ adult females; $n=6$ yearling males; $n=2$ adult males). We also monitored 42 redstarts in second-growth scrub control sites $(n=10$ yearling females; $n=22$ adult females; $n=2$ yearling males; $n=8$ adult males).

Stable-carbon isotope signatures in redstart blood differed between years (for year, $F_{1,19}=33.15, P<$ 0.001 ), but this difference was consistent between treatments (for year $\times$ treatment, $F_{1,19}=0.74, P=0.40$ ) and time periods (for year $\times$ time, $F_{1,20}=0.58, P=$ 0.46 ), so the years were pooled. Stable-carbon isotope values in the blood of birds upgraded to mangrove were indistinguishable from those of control redstarts holding territories in scrub: $-23.88 \%$ $\pm 0.36 \%$ o for controls, $-23.76 \%$ $\pm 0.37 \%$ o for upgrades (mean $\pm \mathrm{SE}$ ), confirming that upgraded individuals originated in scrub habitat. Two months after birds were upgraded, isotopic signatures late in the season were more depleted relative to controls (for controls, $-23.66 \%$ \pm $0.36 \%$; for upgrades, $-25.95 \% \pm \pm 0.37 \%$; for treatment $\times$ time, $F_{1,20}=20.76, P<0.001$; Fig. 1 A), confirming that upgraded redstarts successfully occupied mangrove territories and that control redstarts remained in scrub throughout the winter.

We found no evidence for annual variation in redstart body mass (for year, $F_{1,20}=2.15, P=0.16$ ). Control and upgraded redstarts did not differ in body mass prior to the manipulation $(6.71 \pm 0.05 \mathrm{~g}$ for controls, 6.78 $\pm 0.06 \mathrm{~g}$ for upgrades; mean $\pm \mathrm{SE}$ ), but diverged significantly following the manipulation (for treatment $\times$ time, $F_{1,22}=7.54, P=0.01$; Fig. 1B). On average, upgraded redstarts maintained body mass $(6.80 \pm 0.06$ g), whereas birds in scrub controls lost up to $8 \%$ of early winter mass $(6.52 \pm 0.05 \mathrm{~g})$.

Change in overwinter body mass was positively related to the timing of departure on spring migration $\left(r^{2}\right.$ $=0.20, P=0.03, n=25)$. Upgraded redstarts departed their territories, on average, six days ahead of control birds (Kaplan-Meier log-rank test, $\chi^{2}=6.79, P=0.009$; Fig. 2), a difference that was consistent between years (Kaplan-Meier log-rank test, $\chi^{2}=0.16, P=0.69$ ).

Upgraded redstarts also were more likely to return in the following winter compared to control birds in scrub $\left(\chi^{2}=4.63, P=0.03\right)$. Overall, $59 \%$ of experimentally upgraded redstarts were resighted on or near the mangrove territories that they had occupied in the 

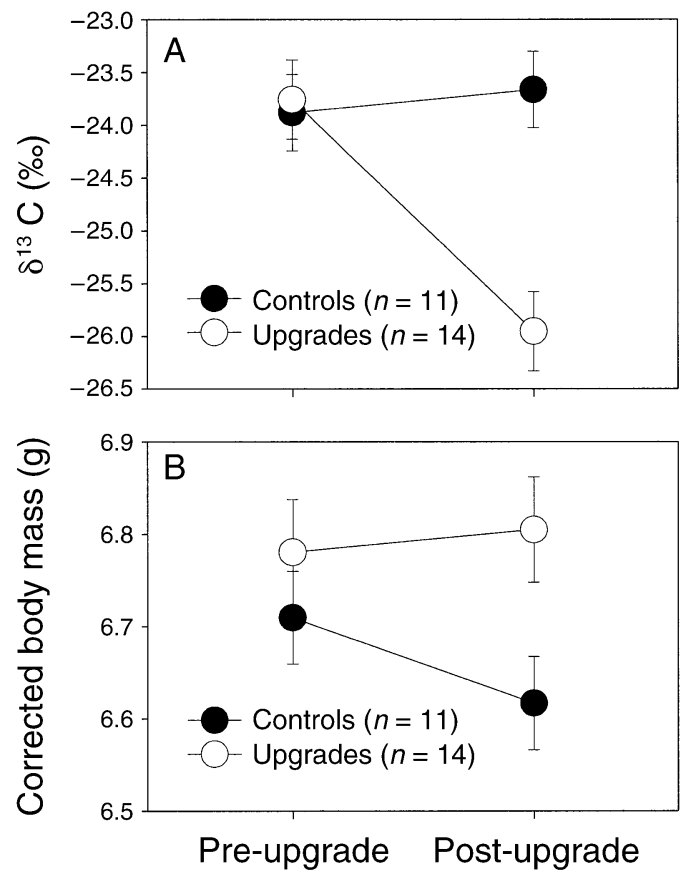

FIG. 1. (A) Stable carbon-isotope values (mean \pm SE) in blood of control American Redstarts occupying second-growth scrub (solid circles) and redstarts experimentally upgraded to mangrove habitat (open circles). (B) Body mass corrected for wing size (mean $\pm \mathrm{SE}$ ) of control and upgraded redstarts. Blood was sampled and body mass was measured immediately prior to the manipulation in winter (pre-upgrade) and two months later in spring (post-upgrade) on the nonbreeding grounds in Jamaica, West Indies.

previous spring, whereas only $33 \%$ of redstarts that had overwintered in scrub were seen on study sites in the following year.

Insect biomass was comparable in both years of the study (for year, $F_{1,19}=0.15, P=0.70$ ). Insect biomass was greater on upgrade than on control territories immediately following the manipulation in winter (5.64 $\pm 1.68 \mathrm{~g}$ for controls, $18.42 \pm 1.74 \mathrm{~g}$ for upgrades; mean $\pm \mathrm{SE})$. Differences in insect biomass between treatments remained pronounced for the duration of the experiment (for treatment, $F_{1,20}=47.71, P<0.0001$; Fig. 3), and were larger in spring (3.51 $\pm 1.68 \mathrm{~g}$ for controls, $19.60 \pm 1.74 \mathrm{~g}$ for upgrades; mean $\pm \mathrm{SE}$ ) than in winter, although not significantly so (for treatment $\times$ time, $\left.F_{1,22}=3.46, P=0.07\right)$.

\section{DISCUSSION}

Few examples exist in which researchers have successfully transplanted or upgraded birds to new habitats (Komdeur et al. 1997). Our experimental upgrade of primarily female and immature male American Redstarts from second-growth scrub to mangrove forest allowed us to convincingly demonstrate that habitat occupancy is a critical factor influencing individual performance measures within winter and annual return rates. Relative to control redstarts overwintering in scrub, birds exper- imentally upgraded to mesic mangrove forest remained in stable physical condition throughout the spring dry season, departed earlier for migration, and returned at a higher rate in the following winter.

Because migratory birds do not mate or breed during winter, the sole benefit of acquiring and defending territories is to access resources needed for maintenance and survival. Evidence to date suggests that food is the most likely resource for which migratory birds compete in winter (Sherry et al. 2005). Food availability has been convincingly linked to patterns of abundance (Johnson and Sherry 2001) and over-winter changes in physical condition (Strong and Sherry 2000, Latta and Faaborg 2002). Insect biomass during this study averaged more than three times greater in mangrove forest than in second-growth scrub, most likely due to the differences in vegetation structure that develop or become exacerbated during the late-winter dry season (Parrish and Sherry 1994). Mangrove forest retains most of its leaves during this period, whereas most plants in second-growth scrub drop their leaves. The more extensive foliage cover in mangrove probably provided both food and refugia for phytophagous insects that comprise much of redstart prey (Sherry and Holmes 1997). Such differences in food availability might account for the variation in springtime physical condition between upgraded and control redstarts.

All upgraded and control redstarts survived through the winter period, suggesting that experimentally induced differences in physical condition did not become limiting until late spring. Birds upgraded to mangrove, which maintained mass, were able to depart on migration in advance of second-growth scrub control birds, which lost mass. Recent research suggests that disparities in physical condition and departure timing induced by differences in winter habitat occupancy may have important consequences in subsequent seasons. Bearhop et al. (2004) demonstrated that migrating Black-throated Blue Warblers (Dendroica caerulescens) that overwintered in

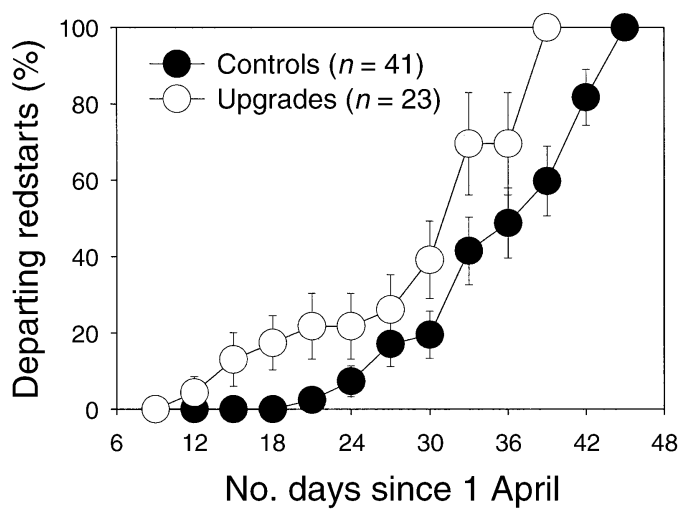

FIG. 2. Spring migration departure schedules (mean $\pm \mathrm{SE}$ ) of control (solid circles) and upgraded (open circles) American Redstarts from the nonbreeding grounds in Jamaica, West Indies. 


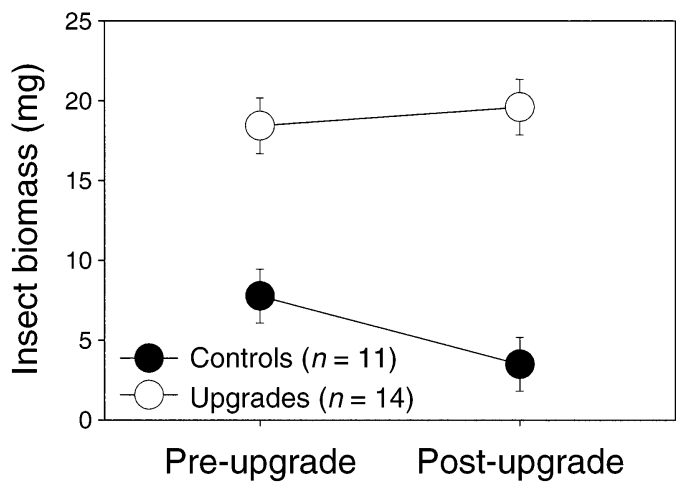

FIG. 3. Biomass of insects (mean \pm SE) available as prey on the territories of control (solid circles) and upgraded (open circles) American Redstarts immediately following the manipulation in winter (pre-upgrade) and two months later in spring (post-upgrade) on the nonbreeding grounds in Jamaica, West Indies.

mesic habitats were in better condition than birds originating from more xeric locations. Other research on redstarts has shown that birds wintering in mesic sites, regardless of sex or age, arrived earlier on breeding grounds (Marra et al. 1998) and, as a result, fledged significantly more young than did birds from more xeric winter habitats (Norris et al. 2004a). Collectively, these findings support the hypothesis that habitat-specific winter physical condition can carry over to subsequent phases of the annual cycle.

Capture-recapture analyses of long-term survival data show the resight probability for American Redstarts in this population to be $>90 \%$ (C. E. Studds and P. P. Marra, unpublished data), evidence that the annual return rates reported here are probably a good indicator of true survival. However, because no analytical method can account for permanent dispersal, we acknowledge that at least some birds that failed to return to their territories in the following year may have survived and wintered in other locations. Nonetheless, the notion that habitatspecific physical condition in winter may ultimately limit survival is important because, when applied to females, it suggests a mechanism by which density-dependent effects could regulate populations (Sherry and Holmes 1995, Runge and Marra 2005). Poor survival of females forced to winter in drought-prone environments like the second-growth scrub habitat studied here could produce a positive density-dependent feedback on per capita reproduction in the following breeding season. Surplus female offspring might then be forced into lowquality habitats in the following winter, where they would experience disproportionately lower survival (Sherry and Holmes 1995).

Understanding how different periods of the annual cycle interact to drive sex ratio dynamics and densitydependent responses such as we have described will require much additional research. First, it will be necessary to improve our knowledge of how variation in physical condition and survival operate in phases of the annual cycle other than winter. Second, it will be necessary to enhance our understanding of migratory connectivity (Webster et al. 2002, Marra et al., in press) so that interactions between population size and demographic rates at different stages of the annual cycle can be examined between appropriate breeding and nonbreeding areas. Such advances will increase our understanding of how populations of migratory animals are regulated and will set the stage for collaborative conservation partnerships between researchers and managers at temperate and tropical latitudes.

\section{ACKNOWLEDGMENTS}

We are grateful to D. Brown, K. Cramer, H. Davis, M. Evans, P. Goulet, Q. Hays, and T. Sherry for excellent assistance in the field, and to R. Greenberg, S. Latta, R. Norris, J. Walters, and one anonymous reviewer for their thoughtful comments on the manuscript. This research was funded by a National Science Foundation DEB-0089565 grant to P. P. Marra (Smithsonian Environmental Research Center). We thank the Petroleum Corporation of Jamaica for permission to conduct this research at the Font Hill Nature Preserve, and the Natural Resources Conservation Authority for their cooperation with our research in Jamaica. Sadie Gordon, Mackie Gordon, Andrew Williams, and Tracey Hawthorne provided generous hospitality and support in Jamaica. Bird removals were conducted in accordance with permits issued by the U. S. Fish and Wildlife Service, the Natural Resources Conservation Authority of Jamaica, and protocols approved by the Institutional Animal Care and Use Committee of the Smithsonian Environmental Research Center.

\section{Literature Cited}

Bayne, E. M., and K. A. Hobson. 2002. Apparent survival of male Ovenbirds in fragmented and forested landscapes. Ecology 83:1307-1316.

Bearhop, S., G. M. Hilton, S. C. Votier, and S. Waldron. 2004. Stable isotope ratios indicate that body condition in migrating passerines is influenced by winter habitat. Proceedings of the Royal Society of London B (Supplement) 271:S215S218.

Burke, D. M., and E. Nol. 1998. Influence of food abundance, nest-site habitat, and forest fragmentation on breeding Ovenbirds. Auk 115:96-104.

Gill, J. A., K. Norris, P. M. Potts, T. G. Gunnarsson, P. W. Atkinson, and W. J. Sutherland. 2001. The buffer effect and large-scale population regulation in migratory birds. Nature 412:436-438.

Johnson, M. D., and T. W. Sherry. 2001. Effects of food availability on the distribution of migratory warblers among habitats in Jamaica. Journal of Animal Ecology 70:546-560.

Komdeur, J., S. Daan, J. Tinbergen, and C. Mateman. 1997. Extreme adaptive modification in sex ratio of the Seychelles warbler's eggs. Nature 385:522-525.

Latta, S. C., and M. E. Baltz. 1997. Population limitation in Neotropical migratory birds: comments on Rappole and McDonald (1994). Auk 114:754-762.

Latta, S. C., and J. Faaborg. 2002. Demographic and population responses of Cape May warblers wintering in multiple habitats. Ecology 83:2502-2515.

Marra, P. P. 2000. The role of behavioral dominance in structuring patterns of habitat occupancy in a migrant bird during the nonbreeding season. Behavioral Ecology 11:299-308.

Marra, P. P., K. A. Hobson, and R. T. Holmes. 1998. Linking winter and summer events in a migratory bird by using stable-carbon isotopes. Science 282:1884-1886. 
Marra, P. P., and R. T. Holmes. 2001. Consequences of dominance-mediated habitat segregation in American Redstarts during the non-breeding season. Auk 118:92-104.

Marra, P. P., D. R. Norris, S. Haig, M. S. Webster, and A. Royle. In press. Migratory Connectivity. In $\mathrm{K}$. Crooks and S. Muttulingam, editors. Maintaining connections for nature. Oxford University Press, New York, New York, USA.

Marra, P. P., T. W. Sherry, and R. T. Holmes. 1993. Territorial exclusion by a long-distance migrant warbler in Jamaica: a removal experiment with American Redstarts (Setophaga ruticilla). Auk 110:565-572.

Møller, A. P., F. de Lope, and N. Saino. 2004. Parasitism, immunity, and arrival date in a migratory bird, the Barn Swallow. Ecology 85:206-219.

Moore, F. R., S. A. Gauthreaux, P. Kerlinger, and T. R. Simons. 1995. Habitat requirements during the migration period: an important link in conservation. Pages 121-144 in T. E. Martin and D. E. Finch, editors. Ecology and management of Neotropical migratory birds. Oxford University Press, New York, New York, USA.

Newton, I. 2004. Population limitation in migrants. Ibis 146 197-226.

Norris, D. R., P. P. Marra, K. T. Kyser, T. W. Sherry, and L. M. Ratcliffe. 2004a. Tropical winter habitat limits reproductive success on the temperate breeding grounds in a migratory bird. Proceedings of the Royal Society of London Series B 271:59-64.

Norris, D. R., P. P. Marra, R. Montgomery, T. K. Kyser, and L. M. Ratcliffe. 2004b. Reproductive effort, molting latitude, and feather color in migratory songbird. Science 306: 1249-1250.

Parrish, J. D., and T. W. Sherry. 1994. Sexual habitat segregation by American Redstarts wintering in Jamaica: importance of resource seasonality. Auk 111:38-49.

Pyle, P. 1997. Identification guide to North American birds. Part 1, Columbidae to Ploceidae. Slate Creek Press, Bolinas, California, USA.

Rappole, J. H., and M. V. McDonald. 1994. Cause and effect in population declines of migratory birds. Auk 111:652-660.

Robinson, S. K., F. R. Thompson, III, T. M. Donovan, D. R. Whitehead, and J. Faaborg. 1995. Regional forest fragmen- tation and the nesting success of migratory birds. Science 267:1987-1990.

Rodewald, A. D., and R. H. Yahner. 2001. Avian nesting success in forested landscapes: influence of landscape composition, stand and nest-patch microhabitat, and biotic interactions. Auk 118:1018-1028.

Runge, M., and P. P. Marra. 2005. A demographic model for a migratory passerine bird: population dynamics of the American Redstart. Pages 375-389 in R. Greenberg and P. P. Marra, editors. Birds of two worlds: the ecology and evolution of temperate-tropical migration systems. Johns Hopkins University Press, Baltimore, Maryland, USA.

SAS Institute. 1999. SAS/STAT Users guide. Version 8.2. SAS Institute, Cary, North Carolina, USA.

Sherry, T. W., and R. T. Holmes. 1995. Summer versus winter limitation of populations: what are the issues and what is the evidence? Pages 85-120 in T. E. Martin and D. E. Finch, editors. Ecology and management of Neotropical migratory birds. Oxford University Press, New York, New York, USA.

Sherry, T. W., and R. T. Holmes. 1997. American Redstart (Setophaga ruticilla). In A. Poole and F. Gill, editors. Birds of North America, Number 277. Academy of Natural Sciences, Philadelphia, Pennsylvania; American Ornithologists' Union, Washington, D.C., USA.

Sherry, T. W., M. D. Johnson, and A. M. Strong. 2005. Does winter food limit populations of migratory birds? Pages 414425 in R. Greenberg and P. P. Marra, editors. Birds of two worlds: the ecology and evolution of temperatetropical migration systems. Johns Hopkins University Press, Baltimore, Maryland, USA.

Sillett, T. S., and R. T. Holmes. 2002. Variation in survivorship of a migratory songbird throughout its annual cycle. Journal of Animal Ecology 71:296-308.

Strong, A. M., and T. W. Sherry. 2000. Habitat-specific effects of food abundance on the condition of Ovenbirds wintering in Jamaica. Journal of Animal Ecology 69:883-895.

Webster, M. S., P. P. Marra, S. M. Haig, S. Bensch, and R. T. Holmes. 2002. Links between worlds: unraveling migratory connectivity. Trends in Ecology and Evolution 17:76-83.

Zanette, L., P. Doyle, and S. M. Tremont. 2000. Food shortage in small fragments: evidence from an area-sensitive passerine. Ecology 81:1654-1666. 